\title{
Factor Intensity Versus Factor Substitution in a Specified General Equilibrium Model
}

\author{
Henry Thompson* \\ Auburn University
}

\begin{abstract}
This paper examines the sensitivity of the comparative static elasticities of a general equilibrium model of production to factor intensity and factor substitution. A model of the US economy is specified with three factors and two goods. Changing factor endowments have consistently inelastic effects on factor prices. Prices of goods, however, have elastic effects on factor prices, and factor endowments have elastic effects on outputs. Factor intensity influences the comparative statics more than factor substitution. Under a move toward free trade characterized by a falling price of manufactures relative to services, the wage of unskilled labor falls while the wage of skilled labor and the price of capital rise.
\end{abstract}

\section{Introduction}

The interplay between factor intensity and factor substitution determines the direction and magnitude of comparative static adjustment in the general equilibrium economics of production. Quite a bit is known about the qualitative nature of general equilibrium models, but there is little intuition about the quantitative properties of comparative static elasticities.

\footnotetext{
* Correspondence Address: Department of Economics, Auburn University, AL 36849, U.S.A. (Tel.) 334-844-2910, (Fax) 334-844-9516, e-mail: hthompsn@business.auburn.edu C1995 - Institute for International Economics, Sejong Institution. All rights reserved.
} 
This paper specifies and examines the comparative statics of a three factor, two good $(3 \times 2)$ model of production and trade. Sensitivity of the comparative static elasticities to translog, Cobb-Douglas, constant elasticity, and complementary technologies is examined. Important insights emerge.

Elasticities of factor prices with respect to changing factor endowments are less than one in absolute value, and typically close to zero. This result is called near factor price equalization (NFPE). Globally, factor prices would be nearly equal across freely trading economies. Stolper-Samuelson and Rybczynski(SSR) elasticities, on the other hand, are typically much larger than one in absolute value. Furthermore, SSR elasticities depend almost entirely on factor intensity and are insensitive to the pattern of factor substitution or complementarity.

Characterizing the trend toward free trade in the US by a falling price of manufactures relative to business services, there will be income redistribution favoring skilled labor and capital over unskilled labor. Also, production patterns can be expected to vary substantially across countries under free trade, driven by international differences in factor endowments.

\section{General Equilibrium Model of Production and Trade}

The long run competitive model of production, summarized by Jones and Scheinkman [1977] and Chang [1979], assumes constant returns, full employment, nonjoint production, competitive pricing, cost minimization, and perfect factor mobility across sectors. The model is summarized by

$$
\left[\begin{array}{ll}
\sigma & \lambda \\
\theta^{\prime} & 0
\end{array}\right]\left[\begin{array}{l}
\hat{w} \\
\hat{x}
\end{array}\right]=\left[\begin{array}{l}
\hat{v} \\
\hat{p}
\end{array}\right],
$$

In the $3 \times 2$ model, $\sigma$ represents a $3 \times 3$ matrix of aggregate price elasticities of factor demand. Factor shares in the $3 \times 2$ matrix $\theta$ represent the share of revenue in each sector paid to each factor. The $3 \times 2$ matrix of industry shares $\lambda$ represents the share of each factor employed in each sector. The variables are written in vectors: $w$ represents endogenous factor prices, $x$ endogenous outputs, $v$ exogenous factor endowments, and $p$ exogenous world prices of goods facing the economy. The ${ }^{\wedge}$ represents percentage changes.

The top equation in (1) comes from the full employment of the factors of 
production: capital, unskilled labor, and skilled labor. The bottom equation is derived from competitive pricing and cost minimization in each industry. The economy is assumed to be a price taker in the international markets for the two finished goods. Comparative static results are local in nature. The $\partial w / \partial p$ and $\partial x / \partial v$ elasticities are symmetric in signs due to Samuelson's reciprocity.

The $3 \times 2$ model teaches some important lessons. Jones [1971] points to its rich production structure and calls it a classical model with inputs of land, labor, and capital. Batra and Casas [1976] argue that strong StolperSamuelson-Rybczynski (SSR) results are necessary, but Suzuki [1982] and Thompson [1983] show that a wider range of SSR results may occur. Thompson [1983] examines conditions under which factor prices polarize (not equalize) across countries in a move to free trade. Takayama [1982] generalizes the model and develops applications. Jones and Easton [1983] and Thompson [1993] provide insight into the model's SSR comparative static mechanism and magnification effects.

\section{Factor Shares and Industry Shares in a 3×2 Model}

Estimates of factor shares in $\theta$ and industry shares in $\lambda$ are crucial for the model specification. Figures on employment are taken from the US Census [1981]. Skilled labor is specified as the two highest paid Census groups: managers/professionals and precision/craft/repair. All results are insensitive to adding or deleting a Census group from this skilled labor category.

Factor input is defined as the dollar value of factor $i$ used in sector $j$,

$$
w_{i j} \equiv w_{i} v_{i j}
$$

where $w_{i}$ is the price of factor $i$ and $v_{i j}$ the quantity of factor $i$ used in sector $j$. The share of factor $i$ in sector $j$ is calculated as

$$
\theta_{i j} \equiv w_{i j} / y_{j}
$$

where $y_{j}$ is the total output of sector $j$. The data are static in nature, taken at a single point in time. Nominal values for factor payments and output are used. Index $i$ runs across the three inputs, capital $(k)$, unskilled labor $(u)$, 
and skilled labor $(s)$. Figures on output by sector come from the US Census [1983, 1984] and US Department of Commerce [1981].

The derived factor share matrix with output split into the major sectors of national output, agriculture $(g)$, manufacturing $(m)$, and services $(c)$, is written

$$
\left[\begin{array}{lll}
\theta_{k g} & \theta_{k m} & \theta_{k c} \\
\theta_{s g} & \theta_{s m} & \theta_{s c} \\
\theta_{u g} & \theta_{u m} & \theta_{u c}
\end{array}\right]=\left[\begin{array}{lll}
.598 & .216 & .256 \\
.146 & .317 & .358 \\
.256 & .467 & .386
\end{array}\right] .
$$

In calculating (4), the labor shares $\theta_{s j}$ and $\theta_{u j}$ come directly from the aggregate payment to each type of labor. The capital shares $\theta_{k j}$ are the residual: $\theta_{k j}=1-\theta_{s j}-\theta_{u j}$.

Industry shares $\lambda_{i j}$ are defined as $v_{i j} / v_{i}$, the portion of factor $i$ employed in sector $j$, and are calculated as

$$
\lambda_{i j}=w_{i j} / y_{i},
$$

where $y_{i}$ is the total income of factor $i$. The industry share matrix is

$$
\left[\begin{array}{lll}
\lambda_{k g} & \lambda_{k m} & \lambda_{k c} \\
\lambda_{s g} & \lambda_{s m} & \lambda_{s c} \\
\lambda_{u g} & \lambda_{u m} & \lambda_{u c}
\end{array}\right]=\left[\begin{array}{lll}
.103 & .217 & .680 \\
.019 & .247 & .734 \\
.006 & .340 & .654
\end{array}\right] .
$$

Services is the largest sector in the US economy, employing about $70 \%$ of every productive factor, about three times as much capital and skilled labor as manufacturing, and about twice the unskilled labor. Agriculture employs very small percentages of labor and about $10 \%$ of the capital stock, which as a residual implicitly includes land.

A $3 \times 2$ model is created by dropping the agricultural sector. Agriculture is small relative to the other sectors, and agricultural production is tightly controlled and highly subsidized. International trade in agricultural goods is also distorted. Agriculture can be aggregated with manufacturing and results are very similar to those reported below.

Factor shares for the $3 \times 2$ model are taken directly from (4),

$$
\left[\begin{array}{ll}
\theta_{k m} & \theta_{k c} \\
\theta_{s m} & \theta_{s c} \\
\theta_{u m} & \theta_{u c}
\end{array}\right]=\left[\begin{array}{ll}
.216 & .256 \\
.317 & .358 \\
.467 & .386
\end{array}\right] \text {. }
$$


Factor intensity in the $3 \times 2$ model is described by ratios of these factor shares, since

$$
\theta_{i j} / \theta_{i h}=\left(v_{i j} / y_{j}\right) /\left(v_{i h} / y_{h}\right) \equiv a_{i j} / a_{i h} \equiv a_{i j h},
$$

where $a_{i j}$ represents the cost minimizing amount of factor $i$ used per unit of output in sector $j$. The factor intensity ranking in this $3 \times 2$ model is

$$
a_{u m c}=1.21>a_{s m c}=0.89>a_{k m c}=0.84 \text {. }
$$

Unskilled labor is the extreme input in manufacturing and capital is the extreme input in services. Skilled labor is the middle factor and much closer to capital in its factor intensity.

Ruffin [1981] shows that extreme factors are migration enemies in the $3 \times 2$ model, regardless of the pattern of substitution. An increase in the endowment of unskilled labor lowers the return to capital, and vice versa. The middle factor skilled labor is a migration friend of both extreme factors. Thompson and Clark [1983] report the pattern of migration friendship for the US economy when agriculture is aggregated with manufacturing.

The industry share matrix can be derived directly from (6) by disregarding the share of inputs employed in agriculture and renormalizing:

$$
\left[\begin{array}{ll}
\lambda_{k m} & \lambda_{k c} \\
\lambda_{s m} & \lambda_{s c} \\
\lambda_{u m} & \lambda_{u c}
\end{array}\right]=\left[\begin{array}{ll}
.242 & .758 \\
.252 & .748 \\
.342 & .658
\end{array}\right] .
$$

\section{Translog Estimation of Factor Substitution}

Estimates of aggregate factor demand elasticities in matrix $\sigma$ in (1) are required to complete a model specification. Each sector's production function is first specified as a translog Taylor series expansion,

$$
\ln x=\ln \alpha_{o}+\sum_{i} \alpha_{i} \ln v_{i}+\frac{1}{2} \sum_{i} \sum_{h} \gamma_{i h} \ln v_{i} \ln v_{h},
$$

where $x$ is output, $v_{i}$ 's are inputs, $\alpha$ 's and $\gamma$ 's are estimated technical coefficients, and $i, h=k, s, u$.

A system of factor share equations, 


$$
S_{i}=\alpha_{i}+\sum_{h} \gamma_{i h} \ln v_{h},
$$

is derived from (11) and estimated across States in the US using iterative Zellner generalized least squares. The number of workers in each skill category by industry for all fifty states is reported by the US Census [1981]. The capital share equation is redundant, and only share equations for skilled and unskilled labor are estimated.

Observations are thus taken across States to estimate factor substitution. The key assumption at work is that there is some difference across States in factor prices and observations of cost minimizing inputs should vary. In the comparative static exercise, the economy is assumed to adjust homogeneously to changes in output prices and factor endowments. The aggregate model assumes perfect mobility of factors inside the country, hence uniform wages and capital rents. The estimation of factor substitution assumes some difference in factor prices across States. The two assumptions are logically at odds. Factor substitution could be estimated, however, with time series data and the sensitivity of the comparative static results to other patterns of substitution is examined.

Allen [1938] elasticities of substitution $S_{i h}$ are found by inverting the derived bordered Hessian matrix of the production function, as clearly presented by Hamermesh and Grant [1979]. Estimates of each sector's factor share equations (12) are in Table 1 . The capital's factor share equation does not need to be estimated since $\gamma_{i k}=\gamma_{k i}, \Sigma_{k} \gamma_{i k}=0$, and $\Sigma_{k} \alpha_{k}=1$. Depreciable capital stock figures by sector across State are taken from the US Census [1983]. Because of a lack of data in services, a Department of Commerce [1981] estimate of the total capital stock in services is split among states

Table 1

Translog Factor Share Estimates (t-values)

\begin{tabular}{|c|ccccc|c|c|}
\hline & $\alpha_{s}$ & $\alpha_{u}$ & $\gamma_{s u}$ & $\gamma_{s k}$ & $\gamma_{u k}$ & $R_{s}^{2}$ & $R_{u}^{2}$ \\
\hline \multirow{3}{*}{$m$} & .2231 & .1206 & -.0978 & -.0100 & -.0167 & .442 & .224 \\
& $(8.23)$ & $(3.38)$ & $(-14.1)$ & $(-1.21)$ & $(-1.55)$ & & \\
\hline \multirow{2}{*}{$c$} & .2507 & .1379 & -.1007 & -.0148 & -.0144 & .012 & .088 \\
& $(3.98)$ & $(1.90)$ & $(-8.54)$ & $(-0.76)$ & $(-0.65)$ & & \\
\hline
\end{tabular}


assuming each employs the same ratio of capital to labor as in manufacturing.

Berndt and Christensen [1973] point out that estimation of (12) assumes constant returns to scale (CRS) and Hicks neutral technical change. As output expands along a linear expansion path, factor shares would all be unchanged given CRS and homotheticity. This structure is tested by estimating

$$
S_{i}=\alpha_{i}+\sum_{j} \gamma_{i k} \ln v_{k}+\delta_{i} x
$$

and testing the null hypothesis that $\delta_{i}=0$. A Chi square test reveals that this null hypothesis cannot be rejected in any sector even at a $90 \%$ confidence level.

Another preliminary test concerns the separability of inputs. The null hypothesis of nonlinear separability is rejected at a $99 \%$ level of confidence except for skilled and unskilled labor in services. There is no evidence of separability in manufacturing, where the data is more detailed.

Let $E_{i h}^{j}$ represent the factor cross price elasticity in sector $j$. Sato and Koizumi [1973] show that cost minimizing behavior implies

$$
E_{i h}^{i}=\theta_{h j} S_{i h}^{i}
$$

Sectoral elasticities are weighted by industry shares to derive the super bowl elasticities in matrix $\sigma$,

$$
\sigma_{i h} \equiv \sum_{j} \lambda_{i j} E_{i h}^{i}
$$

Jones and Easton [1983] summarize properties of the aggregate elasticities $\sigma_{i h}$, which represent the percentage change in the input of factor $i$ for every $1 \%$ percent increase in the price of factor $h$ across the economy. If $\sigma_{i h}$ is positive (negative), the two factors are aggregate substitutes (complements). Homogeneity implies that rows of the negative semidefinite matrix $\sigma$ sum to zero. Estimated own elasticities $\sigma_{i i}$ turn out to be negative, which means the underlying cost functions are locally concave in factor prices.

Using (14), sectoral cross price elasticities are calculated from Table 1. The matrix of manufacturing factor price elasticities $E_{i h}^{m}$ is

$$
\left[\begin{array}{rrr}
-.931 & .367 & .564 \\
.250 & -1.43 & 1.18 \\
.261 & .798 & -1.06
\end{array}\right] \text {. }
$$


Factor price elasticities in services $E_{i h}^{c}$ are

$$
\left[\begin{array}{rrr}
-.879 & .431 & .448 \\
.308 & -1.39 & 1.08 \\
.261 & 1.00 & -1.30
\end{array}\right]
$$

There is no evidence of complementarity in either sector. The largest own elasticities occur for skilled labor, and the smallest for capital. Weighting these factor cross price elasticities as in (15) leads to the matrix $\sigma$ of aggregate translog elasticities which appears in (1):

$$
\left[\begin{array}{lll}
\sigma_{k k} & \sigma_{k s} & \sigma_{k u} \\
\sigma_{s k} & \sigma_{s s} & \sigma_{s u} \\
\sigma_{u k} & \sigma_{u s} & \sigma_{u u}
\end{array}\right]=\left[\begin{array}{rrr}
-.892 & .416 & .476 \\
.294 & -1.40 & 1.11 \\
.285 & .931 & -1.22
\end{array}\right] .
$$

\section{Comparative Statics in the $3 \times 2$ Translog Model}

The $3 \times 2$ translog model in (1) is constructed from (7), (10), and (18). The economy is assumed to be in static equilibrium, and hypothetical small changes in exogenous prices and factor endowments at the national level are introduced. Outputs and factor prices adjust endogenously. Factor shares and industry shares, which form the foundation of the comparative statics, are very stable over time. The following comparative static exercises are thus an experiment which indicate the strength of adjustment in an idealized model. The comparative statics are much too broad for immediate policy applications, but illustrate the quantitative workings of a well known model of production and do provide insight into broad forces. Similar studies with more detail could provide the basis for economic policy.

Inverting (1), the $\partial w / \partial v$ elasticities in the translog model are

$$
\left[\begin{array}{rrr}
-.341 & .378 & -.038 \\
.275 & -.305 & .031 \\
-.029 & .032 & -.003
\end{array}\right]\left[\begin{array}{l}
\hat{v}_{k} \\
\hat{v}_{s} \\
\hat{v}_{u}
\end{array}\right]=\left[\begin{array}{l}
\hat{w}_{k} \\
\hat{w}_{s} \\
\hat{w}_{u}
\end{array}\right] .
$$

These terms are inelastic, suggesting international capital flows and labor migration have relatively little long run impact on the pattern of factor prices. The largest elasticity, the own capital effect, implies that every $10 \%$ 
increase in the capital endowment would lower the price of capital by $3.05 \%$. As a gauge, if the real interest rate were $2 \%$, it would fall to $1.93 \%$.

A $100 \%$ difference in the endowment of unskilled labor between two countries would result in an estimated differences of only $0.3 \%$ in unskilled wages, $3.1 \%$ in skilled wages, and $3.8 \%$ in capital returns. These differences are surprisingly small.

The inelasticity of these $\partial w / \partial v$ terms is referred to as near factor price equalization (NFPE). While the $3 \times 2$ model does not imply complete FPE, static equilibrium factor prices would not be very far apart across freely trading competitive countries. NFPE is robust under various aggregation schemes, as reported by Thompson [1990]. Econometric studies such as Butcher and Card [1991] and LaLonde and Topel [1991] find empirical evidence that immigration has little impact on income distribution.

The $\partial w / \partial p$ Stolper-Samuelson translog elasticities are

$$
\left[\begin{array}{rr}
-8.51 & 9.51 \\
-1.74 & 2.74 \\
7.26 & -6.26
\end{array}\right]\left[\begin{array}{c}
\hat{p}_{m} \\
\hat{p}_{c}
\end{array}\right]=\left[\begin{array}{l}
\hat{w}_{k} \\
\hat{w}_{s} \\
\hat{w}_{u}
\end{array}\right] .
$$

Unskilled labor and capital have a lot at stake when the price of manufactures relative to services changes. This income redistribution closely follows the pattern suggested by factor intensity.

The $\partial x / \partial v$ Rybczynski translog elasticities are

$$
\left[\begin{array}{rrr}
-5.39 & -1.32 & 7.71 \\
2.51 & 1.01 & -2.52
\end{array}\right]\left[\begin{array}{l}
\hat{v}_{k} \\
\hat{v}_{s} \\
\hat{v}_{u}
\end{array}\right]=\left[\begin{array}{c}
\hat{x}_{m} \\
\hat{x}_{c}
\end{array}\right] .
$$

Unskilled labor is again linked strongly with manufactures, while both capital and skilled labor are tied to services. Outputs under free trade would differ substantially across countries with different endowments.

\section{Cobb-Douglas and CES Production in the $3 \times 2$ Model}

Specifications of Cobb-Douglas (CD) and constant elasticity of substitution (CES) production allow a comparison of the translog results with a familiar production technology. Under CD technology, the Allen elasticity of 
substitution $S_{i h}$ equals $1, E_{i h}^{j}=\theta_{h j}$, and $\sigma_{i h}=\Sigma_{j} \lambda_{i j} \theta_{h j}$. The CD substitution matrix is

$$
\sigma_{C D}=\left[\begin{array}{rrr}
-.739 & .336 & .403 \\
.260 & -.660 & .400 \\
.261 & .335 & -.596
\end{array}\right] \text {. }
$$

The strength of substitution is less than in the translog model in (18), especially for skilled and unskilled labor.

The $\partial w / \partial v$ CD elasticities are uniformly slightly larger in absolute magnitude than those the translog model,

$$
\left[\begin{array}{rrr}
-.526 & .584 & -.058 \\
.424 & -.471 & .047 \\
-.045 & .050 & -.005
\end{array}\right]\left[\begin{array}{l}
\hat{v}_{k} \\
\hat{v}_{s} \\
\hat{v}_{u}
\end{array}\right]=\left[\begin{array}{l}
\hat{w}_{k} \\
\hat{w}_{s} \\
\hat{w}_{u}
\end{array}\right] .
$$

The CD production isoquants are slightly less convex than translog isoquants, and changing endowments within the production cone require slightly larger adjustment of the supporting isocost plane.

The largest $\partial w / \partial v$ elasticity is the own capital effect. A $10 \%$ difference in the endowment of capital between two economies would imply a $5.26 \%$ difference in their capital prices. Differences in endowments of unskilled labor across countries would again account for negligible differences in unskilled wages.

Reducing the degree of substitution further with CES production would increase the size of the $\partial w / \partial v$ elasticities in (23) proportionately. For instance, an Allen elasticity of substitution $S_{i n}$ of 0.5 causes the $\partial w / \partial v$ terms to increase $(0.5)^{-1}=2$ times. The capital and skilled labor elasticities in (23) are then elastic. With very inelastic substitution, $S_{i h}=0.1$, the capital and skilled labor elasticities average about 5 in absolute value, but elasticities involving unskilled labor remain inelastic. Increasing the degree of substitution decreases the $\partial w / \partial v$ elasticities proportionately.

Under any CES or CD technology, the SSR elasticities are identical. This property is not noted in the literature, and arises in any model with one more type of factor than good, given homogeneity of the production or cost function. The $3 \times 2 \partial w / \partial p$ elasticities with CES technology are 


$$
\left[\begin{array}{rr}
-5.47 & 6.47 \\
-4.20 & 5.20 \\
7.52 & -6.52
\end{array}\right]\left[\begin{array}{l}
\hat{p}_{m} \\
\hat{p}_{c}
\end{array}\right]=\left[\begin{array}{l}
\hat{w}_{k} \\
\hat{w}_{s} \\
\hat{w}_{u}
\end{array}\right] .
$$

While the sign pattern is the same as in the translog model in (20), effects on the return to capital are smaller and effects on the skilled wage are larger. Effects on the unskilled wage are nearly identical. Skilled labor is a stronger substitute for both capital and unskilled labor in the translog model, because of less convex isoquants and smaller factor price adjustments when exogenous prices change.

The $3 \times 2$ CES $\partial x / \partial v$ Rybczynski elasticities are

$$
\left[\begin{array}{rrr}
-3.44 & -3.48 & 7.93 \\
1.74 & 1.86 & -2.61
\end{array}\right]\left[\begin{array}{l}
\hat{v}_{k} \\
\hat{v}_{s} \\
\hat{v}_{u}
\end{array}\right]=\left[\begin{array}{c}
\hat{x}_{m} \\
\hat{x}_{c}
\end{array}\right] .
$$

This matrix has same sign pattern and similar values as the translog model in (21). Larger effects are associated with skilled labor, while capital effects are smaller. Decreased substitutability for skilled labor and unskilled labor means more convex production isoquants and more output adjustment when the skilled labor endowment changes. Both models have very similar adjustments associated with unskilled labor.

\section{The Potential Influence of Complementarity in the $3 \times 2$ Model}

Strong degrees of technical complementarity between each of the three pairs of factors are introduced in this section to gauge the potential influence of complementarity on the comparative statics. Own substitution elasticities $\sigma_{i i}$ are set to -1 , and the two complementary factors are given equal elasticity of -0.5 . For instance, when capital and skilled labor are complements, the substitution matrix $\sigma$ is

$$
\sigma_{K S}=\left[\begin{array}{rrr}
-1 & -.5 & 1.5 \\
-.5 & -1 & 1.5 \\
.5 & .5 & -1
\end{array}\right]
$$

This strong degree of complementarity between capital and skilled labor is 
referred to as the KS model below. Complementarity between capital and unskilled labor (KU) and between skilled labor and unskilled labor (SU) are similarly formulated.

The $\partial w / \partial v$ elasticities in the three complementary models are

$$
\left[\begin{array}{rrr}
-1.05 & 1.17 & -.117 \\
.849 & -.943 & .094 \\
-.090 & .100 & -.010
\end{array}\right]_{K S}\left[\begin{array}{rrr}
-.253 & .281 & -.028 \\
.204 & -.227 & .023 \\
-.022 & .024 & -.002
\end{array}\right]_{K U}\left[\begin{array}{rrr}
-.272 & .302 & -.030 \\
.220 & -.244 & .024 \\
-.023 & .024 & -.003
\end{array}\right]_{S U}
$$

In the KS model, the $\partial w / \partial v$ elasticities for capital and skilled labor are near unit elasticity. Changing endowments of unskilled labor (down the last columns) have consistently very small effects. Unskilled wages are consistently insensitive to changing endowments (across the bottom rows). Relative to the CD model, $\partial w / \partial v$ elasticities in the KS model are about twice as large, while they are about half as large in both the KU and SU models.

The three sets of $\partial w / \partial p$ elasticities in the complementary models are

$$
\left[\begin{array}{rr}
-8.37 & 9.37 \\
-1.85 & 2.85 \\
7.27 & -6.27
\end{array}\right]_{K S}\left[\begin{array}{rr}
-8.41 & 9.41 \\
-1.82 & 2.82 \\
7.27 & -6.27
\end{array}\right]_{K U}\left[\begin{array}{rr}
-1.59 & 2.59 \\
-7.33 & 8.33 \\
7.85 & -6.85
\end{array}\right]_{S U} \text {. }
$$

This qualitative sign pattern is the same as in the translog and CES specifications. Unskilled labor elasticities along the bottom row are nearly identical in every model specification. Effects on skilled wages and capital are similar in the KS and KU models to the translog model. If skilled labor and unskilled labor were complements, skilled wages would be much more sensitive to price changes. Capital is more insulated in the SU model when it is a strong substitute for both types of labor.

The $\partial x / \partial v$ complementary elasticities are

$$
\left[\begin{array}{rrr}
-3.25 & -3.70 & 7.95 \\
1.71 & 1.90 & -2.61
\end{array}\right]_{K S}\left[\begin{array}{rrr}
-6.27 & -0.34 & 7.61 \\
2.57 & 0.94 & -2.51
\end{array}\right]_{K U}\left[\begin{array}{rrr}
-0.39 & -6.87 & 8.26 \\
0.96 & 2.74 & -2.69
\end{array}\right]_{S U} \text {. }
$$

Unskilled labor elasticities (in the last column) are similar across all model specifications. Other elasticities vary in magnitude, but keep the same sign pattern. When skilled labor and unskilled labor are complements, the output effects of a changing skilled labor endowment are greatly increased and the effects of a changing capital endowment are greatly reduced. 
The high degrees of complementarity introduced in this section do not have drastic effects on the model's comparative statics. Sign patterns remain the same in every model specification. The overriding influence of factor shares and industry shares in the general equilibrium model is apparent.

\section{Conclusion}

Some insights are gained into the comparative static properties of general equilibrium models of production and trade using the present specifications. Elasticities of factor prices with respect to factor endowments are nearly zero, if they are not zero under conditions of factor price equalization. Elasticities of factor prices with respect to prices and elasticities of outputs with respect to endowments are elastic and follow patterns suggested by factor intensity, regardless of factor substitution.

There is evidently quite a bit at stake for productive factors when prices change due to a move toward free trade or to the contrary imposition of protection. Factor price adjustments which occur with these changing prices are large. Given a trend of a declining price of manufactures relative to business services, both capital owners and skilled workers stand to gain in the US. Unskilled labor, used intensively in manufacturing, will suffer.

This insight is reinforced by the property called near factor price equalization. Endowment differences across freely trading countries will have minimal impact on the geographical pattern of factor prices. Production levels, on the other hand, will vary substantially. Given that tastes are similar across nations, the implication is that under free trade international differences in the prices of similar factors will be small, while the volume of international trade will be heavy. The opposite could be expected, namely relatively large factor price differences and a light volume of trade.

Simulation of high dimensional competitive general equilibrium models offers an avenue for advancement in international economics. The underlying theoretical structure is widely studied and understood. Disaggregated and detailed data are available across countries. The present paper suggests that factor intensity, portrayed by factor shares and industry shares, plays a more important role than factor substitution in determining comparative static elasticities. 


\section{References}

Allen, R. G. D. [1938], Mathematical Analysis for Economists, London: MacMillan.

Batra, R., and F. R. Casas [1976], "A Synthesis of the Heckscher-Ohlin and the Neo-Classical Models of International Trade," Journal of International Economics 6; pp. 21-38.

Berndt, E. R., and L. R. Christensen [1973], "The Translog Function and the Substitution of Equipment, Structures, and Labor in U.S. Manufacturing 1929-68," Journal of Econometrics 1; pp. 81-114.

Butcher, K. and D. Card [1991], "Immigrátion and Wages: Evidence from the 1980s," American Economic Review 81; pp. 292-296.

Chang, W. W. [1979], "Some Theorems of Trade and General Equilibrium with Many Goods and Factors," Econometrica 47; pp. 709-726.

Hamermesh, D. S., and J. H. Grant [1979], "Econometric Studies of LaborLabor Substitution and Their Implication for Policy," Journal of Human Resources 14; pp. 309-329.

Jones, R. W. [1971], “A Three-Factor Model in Theory, Trade, and History,” in: Bhagwati et. al., eds., Trade, Balance of Payments, and Growth, Amsterdam: North Holland; pp. 3-21.

Jones, R. W. and S. Easton [1983], "Factor Intensities and Factor Substitution in General Equilibrium," Journal of International Economics 15; pp. 65-99.

Jones, R. W. and J. A. Scheinkman [1977], "The Relevance of the Two-Sector Production Model in Trade Theory," The Journal of Political Economy 85; pp. 909-935.

LaLonde, R., and R. Topel [1991], "Immigrants in the American Labor Market: Quality, Assimilation, and Distributional Effects," American Economic Review 81; pp. 297-302.

Ruffin, R. J. [1981], "Trade and Factor Movements with Three Factors and Two Goods," Economics Letters 7; pp. 177-182.

Sato, R. and T. Koizumi [1973], "On the Elasticities of Substitution and Complementarity," Oxford Economic Papers 25; pp. 44-56.

Suzuki, K. [1983], "A Synthesis of the Heckscher-Ohlin and Neoclassical Models of International Trade: A Comment," Journal of International 
Economics 14; pp. 141-144.

Takayama, A. [1982], "On Theorems of General Competitive Equilibrium of

Production and Trade - A Survey of Some Recent Developments in the

Theory of International Trade," Keio Economic Studies 19; pp. 1-37.

Thompson, H. [1985], "Complementarity in a Simple General Equilibrium

Production Model," Canadian Journal of Economics 18; pp. 616-621.

Thompson, H. [1983], "Free Trade and Factor Price Polarization," European

Economic Review 30; pp. 419-425.

Thompson, H. [1990], "Simulating a Multifactor General Equilibrium Model of Production," International Economic Journal 4; pp. 21-34.

Thompson, H. [1993], "The Magnification Effect with Three Factors," Keio Economic Studies 30; pp. 57-64.

Thompson, H. and D. P. Clark [1983], "Factor Movements with Three Factors and Two Goods in the U.S. Economy," Economics Letters 12; pp. 53-60.

US Bureau of the Census [1981], 1980 Census of Population, Volume 1, Characteristics of the Population, Washington, D.C.

US Bureau of the Census [1983], 1978-1979 Annual Survey of Manufactures, Washington, D.C.

US Department of Commerce [1981], Survey of Current Business, Volume 61, No. 2; pp. 57-60. 